\title{
Life self-determination of graduates of engineering and biotechnology programs of the university: regional practices
}

\author{
Valentina Ivashova ${ }^{1,}$, Evgeny Nesmeyanov ${ }^{2}$, Vladislav Dragulenko ${ }^{3}$, Alexey Erokhin ${ }^{4}$, and \\ Olga Kamalova ${ }^{5}$ \\ ${ }^{1}$ Stavropol State Agrarian University, 12, Zootekhnichesky Lane, Stavropol, 355017, Russia \\ ${ }^{2}$ Don State Technical University, 1, Gagarin Square, Rostov-on-Don, 344000, Russia \\ ${ }^{3}$ Kuban State Agrarian University, 13, Kalinina St., Krasnodar, 350044, Russia \\ ${ }^{4}$ North Caucasus Federal University, 1, Pushkin Str., Stavropol, 355017, Russia \\ ${ }^{5}$ Rostov State Medical University of Ministry of Health of the Russian Federation, 29, \\ Nakhichevansky Lane, Rostov-on-Don, 344022, Russia
}

\begin{abstract}
The article describes the modern vision of the category of "life self-determination" on the example of graduates of engineering and biotechnology programs of a regional university. As part of the study, a review of scientific articles was carried out. We formulated theoretical and instrumental approaches that are relevant for the present time, they are: ensuring a high level of primary professional self-identification of university graduates and high satisfaction with professional competencies; creating conditions for the manifestation of prosocial behavior, satisfaction with the psychological comfort of interpersonal and group interactions; the formed need to participate in the modernization and creation of their modern living environment, including updating the content of the rural way of life; raising awareness among young people about the professions in demand, the needs and priorities of the digital society to develop lifelong learning skills. They provide understanding and modeling of youth policy in the field of professional and life self-determination and contribute to the solution of the state task set in the Decree "On the national development goals of the Russian Federation for the period up to 2030".
\end{abstract}

\section{Introduction}

As part of the task set for the national development goals of the Russian Federation for the period up to 2030, a strategic vector has been set at the state level, showing the importance of self-determination and professional orientation of youth on the principles of justice and universality, through the disclosure of the talents and interests of the younger generation. For the entire education system, the answer to the question about the target settings of educational programs is determined. They consist in ensuring the professional selfdetermination of the younger generation, which is the basis of life self-determination. Thus,

\footnotetext{
* Corresponding author: vivashov@mail.ru
} 
the relevance of the analysis of modern not only theoretical, but also instrumental approaches to the content of the category of "life self-determination" is of great practical importance.

This study of life self-determination affects such categories of future specialists, the relevance of the innovative transformative potential of which increases in connection with the content of their professional activities, which is at the forefront of designing new engineering and biotechnological systems. In addition, the regional need for modern transformations is relevant for rural areas, where there is a situation of an outflow of young people, a lower level of comfort of the living environment, lagging infrastructural conditions for the widespread introduction of digitalization, and others. Let us turn to the world experience of approaches to the study of life self-determination and the modern interpretation of the theory of self-determination in scientific publications.

The authors C. Wang, Y. Zhang, J.D. Moss, E.M. Bonem, C. Levesque-Bristol in their study refer to the analysis of the institutional mechanism of higher education, which stimulates the subsequent use of advanced competencies by graduates in solving specific life problems [1]. Methods of mathematical modeling applied in a sample with a large number of observations (3783 respondents) made it possible to test and confirm the authors' hypothesis. The result of the application of higher education by graduates from the standpoint of the theory of self-determination is determined by the leading role of such factors as satisfaction with professional competencies and professional identification. Thus, the evidence-based conclusions of the authors of the study allow us to formulate an important statement: the better the primary professional self-identification of a graduate of higher education is formed and the higher his satisfaction with professional competencies, the greater the likelihood of successful life self-determination. The institutional mechanism of higher education should ensure constant monitoring of these indicators in the strategic management system.

An interesting approach to questions of life self-determination is found in the work of N. Parisi [2]. In his opinion, young people who strive for self-determination feel the need to participate in the renewal and creation of their modern living environment. DigitalFabrication with a new Do-It-Yourself product can become the tools for active transformation and creation of comfortable and modern living conditions. The approbation took place at the International Summer Academy "Homemade Architecture" with the participation of the FabLab team of the Polytechnic University of Bari. The possibilities of additive printing in architecture can be successfully mastered by graduates of engineering programs and in the future they can be promoted by them as a new trend in rural construction. It is obvious that for modern youth, the comfort of the environment and life plays an important role. Lack of comfort, among other factors, negatively affects the decision to live in rural areas, as a practice of rural lifestyle [3].

The emergence of an extreme situation associated with the COVID-19 pandemic in 2020 led to the need to look at many social processes in a different way, including the positive social practices of the full-time university educational process. So, for example, the authors of the study D. Šakan, D. Žuljevic, N. Rokvic come to the conclusion about how positive or negative emotions associated with communication affect the change in the subjective well-being of people and are consistent with the postulates of the theory of selfdetermination (satisfaction basic psychological needs can play a key role in achieving satisfaction with life in general) [4]. Full-time study at a university provides an opportunity not only to master general cultural and professional competencies, but also to develop creative and cognitive interests, form personal social and professional networks and gain social and psychological experience of interacting with different categories of people, get acquainted, perceive someone else's experience of life self-determination and develop their own trajectory. For our study of the life self-determination of graduates of engineering and 
biotechnology programs of the university, one of the significant indicators is satisfaction with the psychological comfort of interpersonal and group interactions. A high level of satisfaction, in our opinion, is one of the important conditions for the success of the life self-determination of university graduates.

The digital format of education implemented in universities during a pandemic has put forward another important factor in the professional and life self-determination of graduates of the university programs: the ability to learn throughout life, making a conflict-free transition to the professions of the future. The authors of the study E.V. Soboleva, T.N. Suvorova, S.V. Zenkina, M.I. Bocharov emphasize the need to transform career guidance activities as the starting point of professional and, as a consequence, life self-determination in the context of the digitalization of the economy [5]. Their first thesis is aimed at raising awareness among young people in the field of in-demand professions, needs, and priorities of the digital society. The second thesis is the formation of the competence of professional self-determination. Based on empirical data on the needs of young people in addressing issues of professional self-determination, the author's model of a virtual assistant has been developed. For our study, two important approaches to the study of life self-determination are determined: 1) understanding of professional self-determination as a competence that a graduate of a university program, including engineering and biotechnology, should possess; 2) the instrumental level of the implementation of the virtual assistant model, which gives a significant advantage in expanding the awareness of young people in the field of demanded professions, needs, and priorities of the digital society. The possibilities of digital applications for the implementation of the main provisions of the theory of selfdetermination are extensive and university education should provide graduates with a systemic perception and their use for the benefit of their own life self-determination [6,7].

Researchers C. Davidson and A. Ewert call the priority of educational programs of colleges, which give positive effects of professional self-determination - attention to practices and encouragement of prosocial behavior [8]. This approach showed, at the level of analysis of students' opinions, their higher commitment to learning and desire to achieve goals, communication skills, social activity, learning skills and social connections [9, 10]. Thus, the target orientation of student youth towards prosocial behavior increases academic self-discipline, academic self-confidence and self-determination when choosing a professional and life path $[11,12,13,14,15]$. Prosocial behavior, according to researchers, makes it possible to more successfully solve many issues of local communities: personal and social learning, increasing life goals and aspirations [16, 17, 18, 19].

Thus, as a result of the analysis of modern approaches to understanding and their instrumental application in the process of improving the life self-determination of youth, a number of key factors can be identified that increase its success:

- high level of primary professional self-identification of university graduates and high satisfaction with professional competencies;

- creating conditions at the university for the manifestation of prosocial behavior, satisfaction with the psychological comfort of interpersonal and group interactions;

- the formed need to participate in the modernization and creation of its modern living environment, including updating the content of the rural way of life;

- raising awareness of young people in the field of in-demand professions, needs and priorities of the digital society for the development of lifelong learning skills.

\section{Materials and methods}

The empirical part of the study of the life self-determination of graduates of engineering and biotechnology programs of the university was carried out in the Stavropol Territory in 
October 2020. To collect primary sociological information we applied the method of electronic questionnaire through Google Form. In total, 826 people from among the graduate students of engineering and biotechnology programs of the universities in the region took part in it. The survey data were processed in SPSS Statistics (version 21) and presented in a generalized form of statistical distributions. The research toolkit included 45 questions, which are structured in information sections: assessment of the quality and importance of higher education for the future engineer and biotechnologist; life and professional plans of graduates and strategies for their achievement; assessment of job opportunities and expectations from future work; plans for territorial mobility of graduates of engineering and biotechnology programs.

\section{Results and discussion}

Life self-determination as a complex concept includes not only theoretically established positions, such as: understanding of success in life, value orientations, life plan, life program, time perspective of life, which determine the personality's ideas about the future. But also modern approaches in the study and improvement of the life self-determination of graduates of the university programs: focus on a high level of professional selfidentification, satisfaction with professional competencies, lifelong learning; prosocial behavior; needs to transform the social environment and improve its comfort [20].

In these approaches, we see the manifestation of the activity component of the indicators of life self-determination. It is for engineering and biotechnological university programs, whose graduates have become the object of sociological research, that these approaches acquire high relevance due to the nature of their professional activities: modernization and design of new engineering and biotechnological systems [21].

The success of the process of life self-determination can be considered as the awareness of one's abilities, interests and opportunities, the choice of future professional activity, the achievement of the desired social status.

The empirical evidence from the survey is segmented by engineering and biotechnology programs. Of considerable interest are the ranked results of setting goals for graduates for the next 10-20 years. From the list of 17 possible answers, the respondents were asked to choose the 5 most significant goals. In this regard, the total number of answers for each group of respondents exceeds $100 \%$.

The data are presented in the following Table 1.

The first five most significant positions among graduates of engineering programs are associated with the achievement of a high level of material well-being within the next 1020 years $(54.9 \%$ of respondents named this option); building a career trajectory and promotion (49.7\% of respondents named this option); creating a family and raising children ( $47.1 \%$ of respondents named this option); professional achievements (option is named by $46.3 \%$ of respondents) and interesting work (option is named by $45.9 \%$ of respondents). Response rates range from $55 \%$ to $46 \%$. Based on the previously identified indicators of the process of life self-determination, it is possible to draw the following conclusion: graduates of engineering programs have a clear vision of the desired social status, which is manifested in four of the five most significant goals for them (achieving material well-being, career advancement, creating a family and professional achievements). In addition, target attitudes towards interesting work and professional achievements speak not only about the desire for professional self-realization and self-identification, but also about the effective expression of interests in specific achievements. Thus, according to the main indicators of life selfdetermination, one can state a positive result. 
Table 1. The main goals of graduates of engineering and biotechnology programs of the university for the next 10-20 years.

\begin{tabular}{|l|c|c|c|c|}
\hline \multirow{2}{*}{\multicolumn{1}{|c|}{ List of main goals }} & \multicolumn{2}{c|}{$\begin{array}{c}\text { Engineering } \\
\text { graduates }\end{array}$} & \multicolumn{2}{c|}{$\begin{array}{c}\text { Biotechnology } \\
\text { programs' } \\
\text { graduates }\end{array}$} \\
\cline { 2 - 5 } & $\%$ & rank & \% & rank \\
\hline 1. Professional achievements & 46,3 & 4 & 28,6 & 5 \\
\hline 2. Career, promotion & 49,7 & 2 & 57,1 & 3 \\
\hline 3. Interesting work & 45,9 & 5 & 71,4 & 1 \\
\hline 4. High level of material wealth & 54,9 & 1 & 64,3 & 2 \\
\hline 5. Creating a family and raising children & 47,1 & 3 & 35,7 & 4 \\
\hline 6. Continuing education & 6,6 & 14 & 1,7 & 15 \\
\hline 7. High social status & 15,9 & 10 & 14,1 & 11 \\
\hline 8. Public recognition, fame & 2,9 & 15 & 3,1 & 14 \\
\hline 9. Power, the ability to lead people & 8,4 & 13 & 7,1 & 13 \\
\hline 10 Independence, freedom & 17,2 & 9 & 21,4 & 7 \\
\hline 11. Useful social and professional \\
connections & 13,4 & 11 & 21,6 & 6 \\
\hline 12. Own business, entrepreneurship & 17,9 & 8 & 14,3 & 10 \\
\hline 13. Good, loyal friends & 20,3 & 6 & 20,7 & 8 \\
\hline 14. Ability to travel around the world & 19,1 & 7 & 19,8 & 9 \\
\hline 15. Go abroad to live and work & 11,3 & 12 & 13,7 & 12 \\
\hline 16. I don't make plans for the future & 2,5 & 16 & 0,0 & 16 \\
\hline 17. I find it difficult to answer & 2,1 & 17 & 0,0 & 16 \\
\hline
\end{tabular}

As for additional approaches to understanding and improving the factors that have a significant impact on the life self-determination of engineering graduates, the areas of improvement are:

- continuing education or education throughout life (only $6.6 \%$ of respondents consider it important);

- understanding and achieving power as one of the components of social status (only $8.4 \%$ of respondents consider it important);

- transformative potential of social and professional ties (13.4\% of respondents) and high social status $(15.9 \%$ of respondents) and entrepreneurial activity $(17.9 \%$ of respondents).

The analysis of the distribution of the most significant goals for the next 10-20 years for graduates of biotechnology programs differs in engineering intensity of choice, but meaningfully represents the same set of variables. Interesting work is in the first place (71.4\% of respondents named this option); in second place is a high level of material prosperity $(64.3 \%$ of respondents cited this option); in third place are career and career advancement $(57.1 \%$ of respondents named this option). Next, the fourth and fifth places are taken, respectively, by creating a family (35.7\% of respondents) and professional achievements (28.6\% of respondents). It should be noted that the 4 th and 5 th positions in the ranking of the goals of graduates of biotechnology programs differ in a lower intensity of choice from engineering programs and the lower limit is outside of $30 \%$. In addition, we observe a shift in emphasis in goal-setting, which can be assessed as a lower focus on the results of life, as evidenced by the greater choice in favor of interest in work (71.4\%) than in professional achievements $(28.6 \%)$, and in the list of 5 most significant goals it occupies the last 5 th place. 
The level of maturity of life self-determination among graduates of biotechnology programs, in our opinion, is somewhat lower than that of graduates of engineering programs.

Areas for improving the process of life self-determination of graduates of biotechnology programs are: focus on setting and conditions for achieving life and professional goals; mobilization of pro-social potential, entrepreneurial competencies and willingness to learn throughout life.

Summing up the results of the analytical review of the results of ranking the goals of graduates of engineering and biotechnology programs for the next 10-20 years, an important positive conclusion can be noted: the options "I do not make plans for the future" and "I find it difficult to answer" were chosen by the minimum number of participants in the survey of engineering programs $(2.5 \%$ and $2.1 \%$, respectively) and did not choose at all by the participants in the survey of biotechnology programs.

Thus, we can say that at a certain level of maturity, life self-determination is presented in almost all graduates of engineering and biotechnology programs who took part in the survey.

\section{Conclusion}

The carried out theoretical analysis of scientific sources, empirical results of the study of the life self-determination of graduates of engineering and biotechnology programs of the university at the regional level, allow us to draw a number of conclusions.

1. Life self-determination as a complex concept, includes not only theoretically established provisions, such as: understanding of success in life, value orientations, life plan, life program, time perspective of life, which determine the personality's ideas about the future. But also it includes modern approaches in the study and improvement of the life self-determination of graduates of university programs: focus on a high level of professional self-identification, satisfaction with professional competencies, lifelong learning; prosocial behavior; needs to transform the social environment and improve its comfort.

2. The first five most significant positions for graduates of engineering and biotechnology programs coincide in the list and are associated with the achievement of a high level of material well-being within the next 10-20 years; building a career trajectory and promotion; creating a family and raising children; professional achievements, interesting work. But a meaningful analysis of the intensity of responses shows a higher level of maturity of the life self-determination of engineering graduates.

3. Areas for improving the process of life self-determination of engineering graduates are associated with a focus on continuing education or lifelong education; understanding and achieving power as one of the components of social status; transformative potential of social and professional ties, high social status and entrepreneurial activity.

4. Areas for improving the process of life self-determination of graduates of biotechnology programs are: focus on setting and conditions for achieving life and professional goals; mobilization of prosocial potential, entrepreneurial competencies and willingness to learn throughout life.

\section{References}

1. C. Wang, Y. Zhang, J.D. Moss, E.M. Bonem, C. Levesque-Bristol, Research in Higher Education 61 (8), 1002-1026 (2020) 
2. N. Parisi, IOP Conference Series: Earth and Environmental Science 588 (3), 032084 (2020)

3. A.I. Alekseev, O.E. Vasilyeva, V.S. Udovenko, Bulletin of Saint Petersburg University. Earth Sciences 65 (3) (2020)

4. D. Šakan, D. Žuljevic, N. Rokvic, Frontiers in Public Health 8, 583181 (2020)

5. E.V. Soboleva, T.N. Suvorova, S.V. Zenkina, M.I. Bocharov, European Journal of Contemporary Education 9 (3), 603-620 (2020)

6. G. Villalobos-Zúñiga, M. Cherubini, Int. J. of Human Comp. Stud. 140, 102449 (2020)

7. P. Kaveti, M.N. Akbar, 2020 ACM Intern. Conf. Proc. Series 3389205, 34-40 (2020)

8. C. Davidson, A. Ewert, Journal of Experiential Education 43 (3), 299-316 (2020)

9. V. Goncharov, A. Erokhin, O. Kolosova, V. Ivashova, R. Chvalun, V. Berkovsky, IOP Conference Series: Earth and Environmental Science 422 (1), 012127 (2020)

10. O. Nikolenko, L. Zheldochenko, N. Lomova, E3S Web of Conferences 175, 15029 (2020)

11. J.L. Howard, M. Gagné, A. Van den Broeck, N. Ntoumanis, L.G. Pelletier, Motivation and Emotion 44 (4), 534-548 (2020)

12. X. Li, D.T.L. Shek, Assessment and Evaluation in Higher Education 45 (5), 741-757 (2020)

13. T. Krettenauer, R. Curren, Journal of Moral Education 49 (3), 275-281 (2020)

14. L. Cronin, D. Marchant, L. Johnson, J. Varga, P. Ellison, Psychology of Sport and Exercise 49, 101711 (2020)

15. S.A. Hooker, K.S. Masters, K.W. Ranby, Psychology of Sport and Exercise 49, 101704 (2020)

16. E.A. Vorobeva, O.A. Mukhoryanova, I.P. Savchenko, I.V. Taranova, E.E. Shidakova, Advances in Intelligent Systems and Computing 726, 173-181 (2019)

17. V. Ivashova, G. Tokareva, E. Agalarova, Y. Nadtochiy, I. Yushchenko, IOP Conference Series: Materials Science and Engineering 775 (1), 012020 (2020)

18. O. Mukhoryanova, K. Hercegová, S. Kalyugina, O. Tretyakova, Terra Economicus 16(4), 130-143 (2018)

19. M. Yasué, J. Kirkpatrick, A. Davison, Conservation and Society 18 (3), 268-279 (2020)

20. V.N. Goncharov, E.E. Nesmeyanov, O.U. Kolosova, V.V. Arutyunyan, V.A. Ivashova, Journal of Physics: Conference Series 1353(1), 012135 (2019)

21. V.N. Goncharov, A.M. Erokhin, V.A. Ivashova, L.A. Tronina, O.N. Kamalova, IOP Conference Series: Earth and Environmental Science 422(1), 012124 (2020) 